\title{
Anti-inflammatory action of insulin via induction of Gadd45- $\beta$ transcription by the mTOR signaling pathway
}

This article was published in the following Dove Press journal:

Hepatic Medicine: Evidence and Research

23 June 2010

Number of times this article has been viewed

\author{
Katherine D Bortoff ${ }^{\prime}$ \\ Adam B Keeton' \\ J Lee Franklin' \\ Joseph L Messina ${ }^{1,2}$ \\ 'Department of Pathology, Division \\ of Molecular and Cellular Pathology, \\ The University of Alabama at \\ Birmingham, Birmingham, Alabama, \\ USA; ${ }^{2}$ Veterans Affairs Medical Center, \\ Birmingham, Alabama, USA
}

Correspondence: Joseph L Messina Department of Pathology, Division of Molecular and Cellular Pathology, VH G019, 1530 3rd Ave S., University of Alabama at Birmingham, Birmingham, AL, 35294-0019, USA

Tel + I (205) 934-492I

$\mathrm{Fax}+\mathrm{I}(205) 975-\mathrm{II} 26$

Email messinaj@uab.edu

\begin{abstract}
Insulin regulates a large number of genes in a tissue-specific manner. We have previously identified genes modulated by insulin in the liver and in liver-derived cells that have not yet been characterized as insulin regulated, and results of these previous studies indicated that numerous genes are induced by insulin via the MEK-ERK pathway. We now describe new studies indicating that Gadd45- $\beta$ can be induced by acute insulin treatment. Although other regulators of Gadd45- $\beta$ expression may utilize the MEK-ERK pathway, the data indicate that insulin utilizes signaling pathways separate from either MEK-ERK, PI3-K, or p38 signaling pathways in the regulation of Gadd45- $\beta$ transcription. Our findings show that activation of a downstream effector of multiple signaling pathways, mTOR, was required for insulin-induction of Gadd45- $\beta$ gene transcription. Increased expression of Gadd45- $\beta$ can inhibit c-Jun N-terminal kinase (JNK) activity. Since TNF $\alpha$ is increased during inflammation, and acts, at least in part, via the JNK signaling pathway, insulin induction of Gadd45- $\beta$ suggests a mechanism for the anti-inflammatory actions of insulin.
\end{abstract}

Keywords: insulin, Gadd45- $\beta$, mTOR, ERK, PI3-kinase, p38, JNK

Insulin regulates hepatic cellular processes involved in normal metabolism, development, and growth, including enzyme activity, gene transcription, and DNA and protein synthesis. ${ }^{1}$ In response to insulin binding, the insulin receptor becomes an active tyrosine kinase resulting in tyrosine autophosphorylation of the insulin receptor and phosphorylation of insulin receptor substrate (IRS) proteins, Son of Sevenless (SOS), and the growth factor receptor binding protein [GRB-2 ${ }^{2}$. This signaling cascade leads to the activation of Ras and MEK kinase, which in turn activates the extracellular signal-regulated kinases [ERK $\left.1 / 2 ;{ }^{3}\right]$.

A second major insulin-regulated signaling pathway is the phosphatidylinositol 3-OH-kinase (PI3-K) pathway, which is activated by recruitment of effector molecules to the tyrosine phosphorylated IRS proteins. In some systems, insulin activates several additional pathways, including those of p38 kinase and Cbl/CAP. ${ }^{2}$ Results of our previous work demonstrated that complex coordination of signaling pathways activated by insulin, including interactions of insulin-activated MEK-ERK and p38 signaling pathways, and the MEK-ERK and PI3-K pathways rapidly induced transcription of the c-fos, Pip92 (also known as CHX-1, ETR101, IER2), Egr-1 (NGF-1A, Krox24, zif268, and TIS8), ATF-3 (LRF-1, LRG-21, CRG-5, and TI-241), Insig-1 (CL-6), and Krox20 (EGR-2) genes. ${ }^{4-6}$ We have also observed that insulin-induced gene expression depends not only on activation of signaling pathways, but the temporal expression patterns of these pathways. ${ }^{6}$ 
Another insulin activatable kinase, downstream of multiple signaling pathways, is mammalian target of rapamycin $\left[\mathrm{mTOR} ;^{7-10}\right]$. This pathway is important in both insulin and in nutrient signaling. The activity of mTOR is inhibited by the fungal antibiotic rapamycin, which blocks the phosphorylation and activation of p70-S6 kinase and 4E-BP1, which are substrates of mTOR..$^{8,11-14}$

We have utilized the H4IIE rat hepatoma cells as a model system. ${ }^{15,16}$ These cells express functional insulin and growth hormone receptors, respond to physiologic concentrations of both, ${ }^{17,18}$ and this response has been utilized in the study of intracellular signaling and subsequent gene expression. We previously identified several insulin-responsive genes through differential screening of an insulin/anisomycin treated cDNA library isolated from H4IIE cells. ${ }^{19}$ These include cytoskeletal genes, and genes involved in cell division and the response to cellular stress. ${ }^{4-6,20-24}$ Many of these genes are described as immediate early genes (IEG) due to their rapid activation in response to insulin. ${ }^{1,25}$

An additional cDNA that was recently selected was identified to be homologous to Gadd45- $\beta$. The Gadd45 isoforms $(\alpha, \beta, \gamma)$ function in common, but also by distinct pathways. ${ }^{26}$ They are induced by a number of cell stressors and have a number of cellular functions, including cell cycle regulation, from which they derive their names, growth arrest and DNA damage-inducible factors. ${ }^{27}$ Their increased abundance contributes to a low mitotic index and protection of genomic integrity. ${ }^{26}$ Conversely, they are downregulated in hepatocellular carcinoma. ${ }^{28}$ Gadd $45-\beta$ is a major player in NFKB mediated resistance to apoptosis and antagonizes TNF $\alpha$ cytotoxicity by suppressing TNF $\alpha$ induced c-Jun N-terminal kinase (JNK) activation. The Gadd45- $\beta$ protein forms a complex with MKK7, the upstream regulator of JNK, inhibiting JNK activation. . $7,29,30^{2}$

In addition to the many metabolic actions of insulin, it plays the role of an anti-inflammatory agent. Insulin reduces proinflammatory mediators such as TNF $\alpha$, IL6, JE, and KC in animal models of endotoxemia. ${ }^{31}$ Several proinflammatory cytokines, in particular IL-6, signal via STAT3. We and other researchers have found that an anti-inflammatory action of insulin is to decrease STAT3 activity. ${ }^{32-34}$ Our recent work indicates that the JNK pathway plays a role in TNF $\alpha$ dependent injury-induced hepatic insulin resistance. ${ }^{35} \mathrm{TNF} \alpha$ is increased during inflammation, and can lead to insulin resistance, at least in part via activating JNK.

Regulation of Gadd45- $\beta$ is complex and may involve multiple signaling pathways. To our knowledge, the present study is the first report demonstrating active insulin-induced transcription of Gadd45- $\beta$. Inhibition of the MEK-ERK and PI3-K pathways were ineffective in altering the insulin effect on Gadd45- $\beta$ transcription. However, mTOR was found to be necessary, since inhibition of this kinase abolished insulininduced Gadd45- $\beta$ transcription. Since insulin increased expression of Gadd45- $\beta$, which can inhibit JNK activity, insulin induction of Gadd45- $\beta$ suggests a mechanism for the anti-inflammatory actions of insulin.

\section{Materials and methods Materials}

Swim's 77 medium, fetal bovine serum, calf serum, horse serum, and wortmannin were obtained from Sigma-Aldrich, (St Louis, MO). RNase $\mathrm{H}$, and proteinase $\mathrm{K}$ were purchased from Gibco/BRL (Bethesda, MD). RNAsin was obtained from Promega (Madison, WI), DNase I and RNase T1 from Worthington/Cappel Biochemicals, Inc. (Lakewood, NJ). LY294002 was purchased from Biomol (Plymouth Meeting, PA), PD98059 was obtained from Cell Signaling Technology (Beverly, MA) as were phospho-(active)-ERK1/2, phospho-(Ser473)-Akt, and secondary rabbit antisera, and International Chemical and Nuclear Corp. (ICN, Costa Mesa, CA) supplied the $\alpha-{ }^{32} \mathrm{P}-\mathrm{UTP}$.

\section{Cell culture}

Rat H4-IIE hepatoma cells (American Type Culture Collection, Rockville, MD) were maintained in monolayer cultures in Swim's 77 medium supplemented with 2\% fetal bovine serum, $3 \%$ calf serum, and 5\% horse serum in a $5 \% \mathrm{CO}_{2}$ incubator. ${ }^{4,17,19}$ Experiments were initiated after serum was withdrawn for 20 to 24 hours when cells were approximately $70 \%$ to $80 \%$ confluent.

\section{Transcription assays}

Transcription rates of the mRNAs of interest were measured in isolated nuclei by the nuclear run-on method exactly as described previously., ${ }^{5,17,19}$ Newly transcribed nuclei were labeled with ${ }^{32} \mathrm{P}-\mathrm{UTP}$. The nascent transcripts were isolated, hybridized with cDNAs dot-blotted onto nitrocellulose, then exposed to autoradiography. The resultant autoradiograms were densitometrically scanned and analyzed using ZeroD Scan from Scanalytics (Fairfax, VA). The values from the treatments were compared to the control in each experiment and expressed as fold-changes.

\section{Western blot analysis}

Whole cell lysates were resolved by SDS-PAGE and transferred to Protran BA85 membranes (Schleicher and Schuell, 
Keene, NH), developed with ECL Plus (Amersham Biosciences, Buckinghamshire, England), and visualized by autoradiography or direct digital imaging of chemiluminescent blots using the Fluorchem FC imager system [Alpha Innotech, San Leandro, $\left.\mathrm{CA}^{4,18,36}\right]$. Quantitation of the relative band intensity and background subtraction was carried out using the onboard software of the Fluorchem FC digital imager., 47,38

\section{Statistical analysis}

ANOVA and Student's $t$ tests were performed using the Instat program (Graphpad Software Inc., San Diego, CA). Values from experimental treatments were expressed as fold changes compared to the vehicle-treated controls within each experiment. \#, \#\#, and \#\#, designate $P<0.05, P<0.01$, and $P<0.001$, respectively, versus vehicle control.

\section{Results}

A cDNA library was constructed from H4IIE cells treated with a postprandial concentration of insulin $\left(1 \times 10^{-8} \mathrm{M}\right)$ and anisomycin $(100 \mu \mathrm{M})$ for 2 hours. Radiolabeled cDNAs isolated from similarly treated cells were then compared with labeled cDNAs from untreated cells in the screening of this library. ${ }^{19}$ Gadd $45-\beta$ was selected as a differentially expressed mRNA. When independently tested using the nuclear run-on assay, a consistent and significant 2- to 3-fold increase of Gadd45- $\beta$ transcription was induced by addition of insulin for 30 minutes $(P<0.001$; Figures $1 \mathrm{~A}$ and $\mathrm{B})$.

It was then asked which insulin-induced signaling pathway(s) was necessary for insulin to increase Gadd45- $\beta$ gene expression. In our prior reports it was demonstrated that the MEK-ERK pathway is required for the rapid insulin induction of c-fos, Pip92, Egr-1, ATF-3, Insig-1, and Krox20 transcription. ${ }^{4-6}$ A specific inhibitor of MEK, PD98059, was used in these prior studies and found to abolish insulin-induced transcription of these genes. When PD98059 was used to determine the requirement for the MEK-ERK pathway in insulin induction of Gadd $45-\beta$ transcription, the inhibitor itself had no effect on basal Gadd45- $\beta$ transcription. Unlike our earlier observations regarding insulin regulation of c-fos, Pip92, Egr-1, ATF-3, Insig-1, and Krox20 transcription, insulin-induced transcription of Gadd45- $\beta$ was not significantly attenuated by pretreatment with PD98059 (Figure1B). This slight but insignificant effect on insulininduced Gadd45- $\beta$ transcription was observed at time points where insulin-stimulated phosphorylation of ERK1/2 was completely blocked. For instance, insulin for 5 minutes resulted in a maximal activation/phosphorylation of ERK1/2 (Figure 1C, top panel). The phosphorylation of ERK1/2

\section{A}

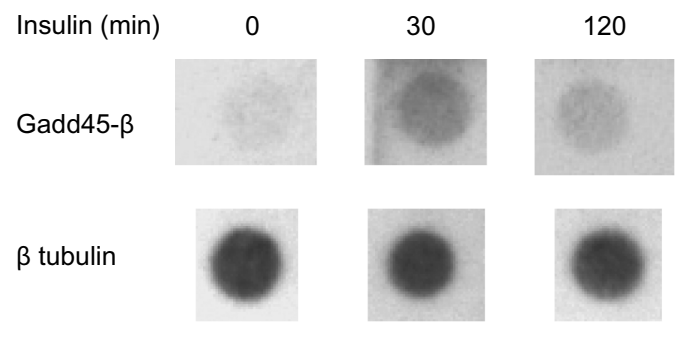

B

Gadd45- $\beta$

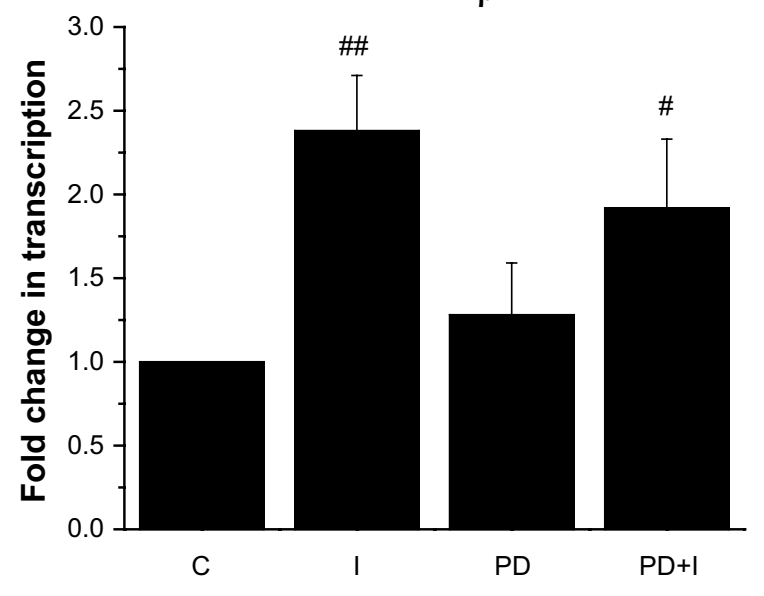

C
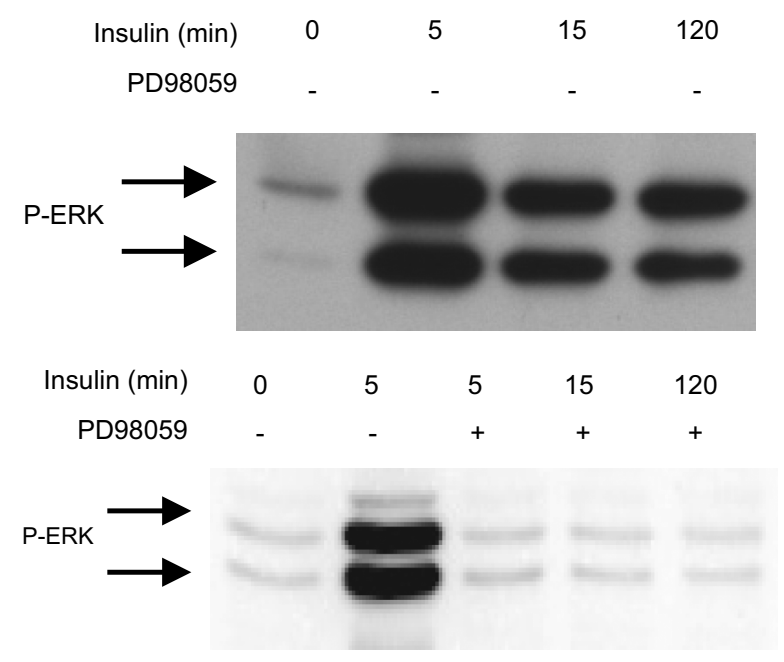

Figure I Induction of Gadd45- $\beta$ transcription by insulin is independent of MEK activity. Serum-deprived H4IIE cells were treated with $10 \mathrm{nM}$ insulin alone for 30 minutes (I) or in the presence of the MEK inhibitor PD98059 (PD; $50 \mu \mathrm{M}$ ) added 30 minutes prior to the insulin. Transcription was measured by nuclear run-on assay as described in Material and methods. (A and B). Levels of ERKI/2 phosphorylation (C) were determined by Western blot of whole cell lysates using phospho-specific antisera. Representative autoradiograms are shown (A and $\mathbf{C})$ along with mean data and standard error (SEM) collected from three or more experiments at each time point (B). Statistical significance: $\#=P<0.05$ and $\#=P<0.01$ versus vehicle control.

decreased by about half by 15 minutes and was still measurably increased following 120 minutes of continuous insulin treatment. Pretreatment of cells with PD98059 completely abolished insulin-activation of ERK1/2 to levels similar to 
levels observed in vehicle controls at all time points tested (Figure 1C, bottom panel). Since phosphorylation of ERK1/2 was completely blocked by the MEK 1 inhibitor, yet insulin induction of Gadd45- $\beta$ transcription was not significantly altered, this indicates that the MEK-ERK pathway alone is not a primary signaling pathway used by insulin to regulate Gadd45- $\beta$ transcription.

A second major signaling pathway activated by insulin, the PI3-K pathway, was then investigated to discover whether insulin regulated transcription of Gadd45- $\beta$ was dependent on this signaling pathway. Insulin treatment rapidly increased signaling via PI3-K as shown by a rapid increase in phosphorylation/activation of the PI3-K effector Akt (Figure 2A). This increase in PI3-K activity by insulin was blocked by pretreatment with a competitive inhibitor of PI3-K, LY294002. However, there was no alteration in either basal or the insulin induction of Gadd $45-\beta$ transcription in the presence of two concentrations of this inhibitor (Figure 2B). A second, less specific inhibitor of PI3-K, wortmannin, which binds to the catalytic p110 subunit of PI3-K, was also used. Similar to the action of LY294002, wortmannin alone did not affect basal transcription levels of Gadd45- $\beta$, nor did it significantly alter insulin-induced Gadd45- $\beta$ transcription (data not shown). Thus, it is unlikely that the PI3-K pathway alone, and its downstream kinase signaling cascade, is a primary signaling pathway used by directly insulin in regulation of Gadd $45-\beta$ transcription.

We previously demonstrated that the p38 pathway, a parallel MAPK signaling pathway regulated by insulin, may negatively regulate ERK1/2 signaling and gene transcription in H4IIE cells. ${ }^{4,5}$ A specific inhibitor of p38, SB202190, was used to assess whether inhibition of $\mathrm{p} 38$, (which would in turn increase ERK1/2 activity) would affect insulininduction of Gadd45- $\beta$ transcription. However, pretreatment of H4IIE cells with SB202190 alone significantly induced Gadd45- $\beta$ transcription $(P<0.01)$, to a level at least equal to that observed with insulin alone (Figure 3). Pretreatment with SB202190 followed by insulin stimulation resulted in an additive or possibly synergistic induction (7.4-fold) of Gadd45- $\beta$ compared to the induction by either insulin or SB202190 treatment alone (2.4- or 3.5-fold, respectively). This suggests that the p38 pathway is a negative regulator of Gadd $45-\beta$ transcription.

It was then asked whether the additive induction of Gadd45- $\beta$ gene transcription by insulin and SB202190 required the activation of the MEK-ERK pathway. For these studies, H4IIE cells were pretreated with PD98059 prior to the addition of SB202190 and insulin. This treatment
A

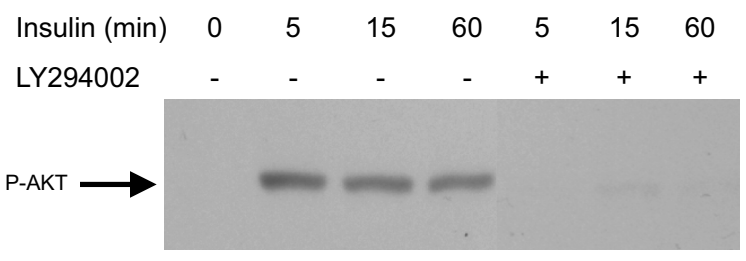

B

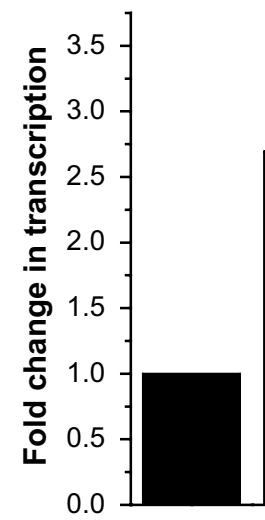

Insulin (min) 0 LY294002 $(\mu \mathrm{M}) \quad 0$

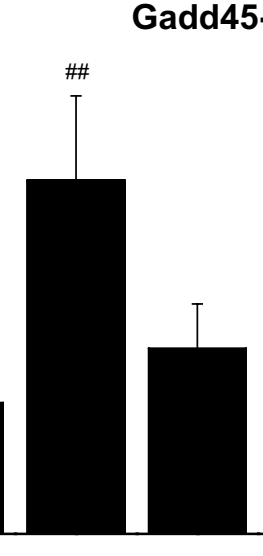

30

0

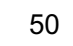

30

50

30

100

Figure 2 Induction of Gadd45- $\beta$ transcription by insulin is independent of PI3-K activity. Serum-deprived H4IIE cells were treated with $10 \mathrm{nM}$ insulin alone for 30 minutes or in the presence of the PI3-K inhibitor, LY294002 (at 50 or $100 \mu \mathrm{M}$, as indicated), added 30 minutes prior to the insulin. Whole cell lysates were prepared and Western analysis was performed. A representative autoradiogram demonstrating levels of Akt Ser-473 phosphorylation is shown (A). Transcription rates were measured by nuclear run on assays and $(\mathbf{B})$ the mean data was collected from three or more experiments at each time point. Statistical significance: \#\#= $P<0.0$ I versus vehicle control.

eliminated the additive/synergistic effect of SB202190 and insulin on Gadd45- $\beta$ transcription, decreasing it to the level of the insulin effect alone (Figure 3). Thus, the SB202190 effect was inhibited by PD98089 addition, and the MEKERK signaling pathway was utilized, as we have recently described in the study of other insulin regulated genes. ${ }^{4,5}$ In contrast, the insulin effect was not blocked by PD98059 when cells were treated with insulin alone or in combination with SB202190 (Figures 1B and 3), again suggesting that insulin uses multiple pathways, or a separate pathway.

To determine if insulin-regulation of Gadd $45-\beta$ transcription occurred via insulin activation of mTOR, cells were pretreated with rapamycin for 60 minutes followed by insulin stimulation for 30 minutes. Rapamycin itself had no effect on basal Gadd45- $\beta$ gene transcription (Figure 4); however, rapamycin completely inhibited the insulin induction of Gadd45- $\beta$, decreasing transcription to basal levels. This indicates that the mTOR pathway is important for insulin's regulation of Gadd $45-\beta$ gene expression. 


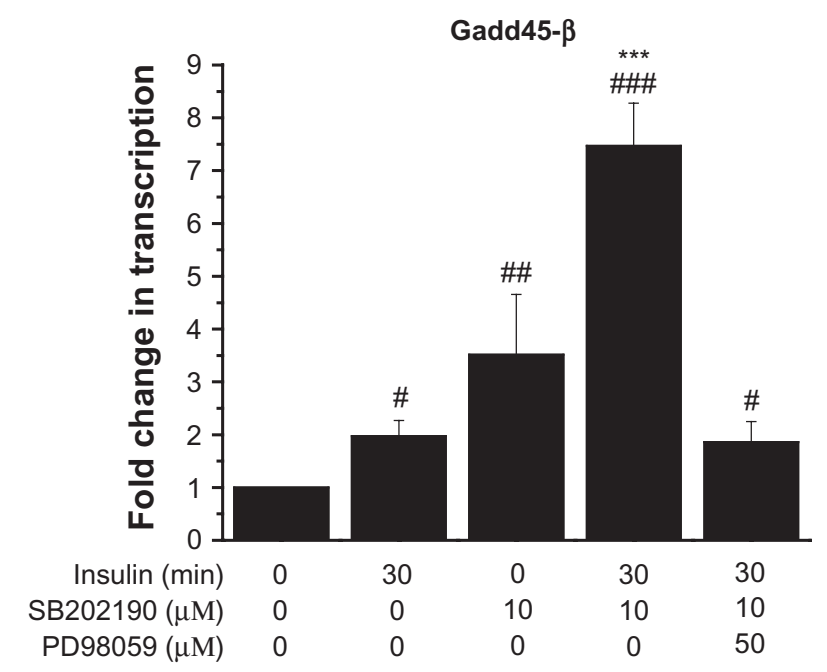

Figure 3 Effect of MEKI and p38 inhibition on induction of Gadd45- $\beta$ transcription by insulin. H4IIE cells were serum-deprived and pretreated with PD98059 $(50 \mu \mathrm{M})$ prior to the addition of SB202190 (10 $\mathrm{M})$ with or without insulin $(10 \mathrm{~nm})$ for 30 minutes. Transcription was then measured by nuclear run-on assays. The mean data was collected from three or more experiments at each time point. Statistical significance: \#, \#, and \#\#, designate $P<0.05, P<0.01$, and $P<0.001$, respectively versus vehicle control. $* * *=P<0.001$ versus insulin treated and SB202190 treated groups.

\section{Discussion}

While searching for insulin-induced genes, we selected a cDNA that was inducible by insulin, and, when sequenced, this cDNA encoded Gadd45- $\beta$, one of a family of growth arrest and DNA damage-inducible genes. To our knowledge, this is the first report of an insulin effect on expression of the Gadd $45-\beta$ gene.

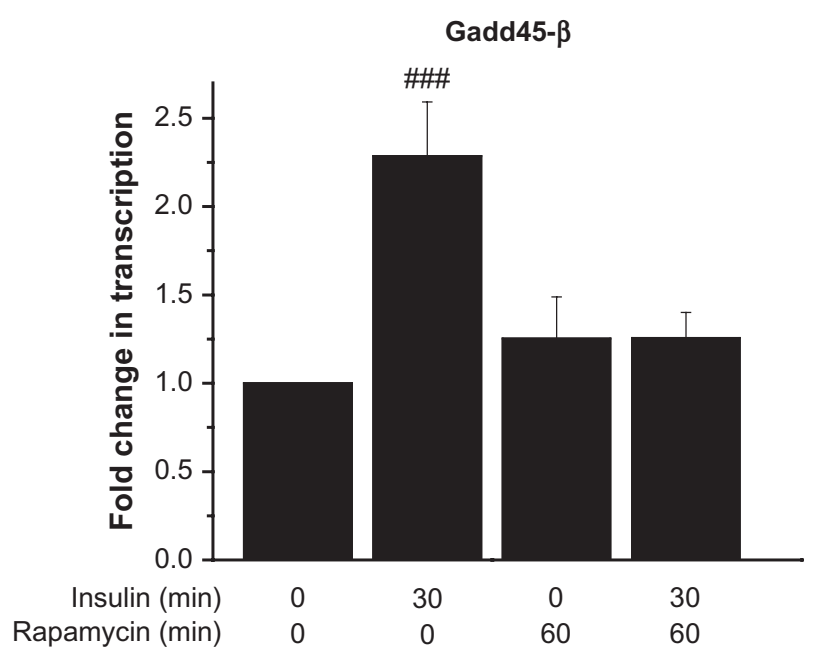

Figure 4 Inhibition of insulin-regulated Gadd45- $\beta$ transcription by rapamycin. Serum-deprived H4IIE cells were treated with $10 \mathrm{nM}$ insulin alone for 30 minutes or in the presence of the mTOR inhibitor, rapamycin (10 $\mu \mathrm{M})$, added 30 minutes prior to the insulin. Nuclear run-on assays were then performed. The mean data was collected from three or more experiments at each time point. Statistical significance: \#\# $=P<0.001$ versus vehicle control.
We then examined which signaling pathway(s) are used by insulin in the regulation of Gadd45- $\beta$ transcription. We have previously reported on the involvement of the MEK-ERK and p38 signaling pathways in insulin-regulated gene expression. For instance, the rapid induction of ERK was absolutely necessary for insulin-induction of c-fos, Pip92, Egr-1, ATF-3, Insig-1, and Krox 20 transcription. ${ }^{4,5,39}$ We therefore expected that this would be the case for insulin induction of Gadd45- $\beta$. However, unlike these other genes, blocking insulin-induced activation of MEK-ERK had little effect on insulin-regulated transcription of Gadd45- $\beta$, suggesting that the MEK-ERK signaling pathway was not a major pathway in insulin regulation of Gadd45- $\beta$ transcription.

This finding, that insulin does not use the MEK-ERK pathway, contrasts with the published accounts on the involvement of MEK-ERK in Gadd45 gene expression. For instance, MEK-ERK is necessary for the full induction of the Gadd45 promoter following UV-induced DNA damage in both HCTII6 human colorectal carcinoma cells and MCF-7 human breast cancer cells. ${ }^{37}$ Also, inhibition of ERK activity decreases Gadd45 expression in the ovarian carcinoma cell line A2780 in response to cisplatin-induced DNA damage. ${ }^{41}$ The present data indicate that insulin does not regulate Gadd45 expression via the MEK-ERK pathway; rather, the data suggest that the $\mathrm{p} 38$ pathway is a negative inhibitor of Gadd45- $\beta$ transcription, and when the $\mathrm{p} 38$ pathway is inhibited, both MEK-ERK signaling and Gadd45- $\beta$ expression are increased. This is similar to our previous observations that inhibition of p38 activity results in activation of the MEK-ERK pathway., ${ }^{4,5}$ However, when the MEK1 (MEKERK) inhibitor was added prior to addition of SB202190 and insulin, transcription of Gadd45- $\beta$ was reduced only to the levels observed with insulin treatment alone. These data demonstrate that activation of the MEK-ERK pathway can result in induction of Gadd45- $\beta$ transcription in the rat H4IIE hepatoma cell line, and that even though insulin is a strong activator of the MEK-ERK pathway, this pathway is not utilized by insulin in the regulation of Gadd45- $\beta$ transcription in H4IIE cells.

Clearly, inhibition of PI3-K signaling also did not alter basal or insulin-induced regulation of the Gadd45- $\beta$ gene. An additional component of insulin signaling is the mTOR kinase, which is important in controlling protein synthesis and cell proliferation in response to changes in nutrients. ${ }^{12,14,42-45}$ The present studies demonstrated that treatment of $\mathrm{H} 4$ cells with rapamycin, an inhibitor of mTOR activity, completely blocked insulin's induction of Gadd45- $\beta$ gene transcription. Since blocking an upstream activator of mTOR, PI3-K, 
had no effect on insulin regulated Gadd45- $\beta$ transcription, it suggests that activation of PI3-K is not the main or only signaling pathway used by insulin to activate mTOR in these cells. While PI3-K has been found to be a common activator of mTOR in many cells, in skeletal muscle passive stretch induces mTOR independent of the PI3-K pathway ${ }^{46}$ and other reports have implicated phospholipase D (PLD) in mTOR signaling. ${ }^{47,48}$ Most evidence suggests that the MEKERK pathway is separate from, but may impinge upon, the mTOR signaling pathway downstream of the mTOR complex (mTORC $\left.{ }^{49-52}\right)$.

In summary, our findings suggest that neither the MEKERK nor PI3-K signaling pathways are predominantly used in insulin regulation of Gadd45- $\beta$. Thus, we propose that some other insulin-responsive pathway is necessary to activate mTOR and insulin-dependent mTOR-regulated Gadd45- $\beta$ transcription, suggesting a novel mechanism for insulin regulation of Gadd $45-\beta$ transcription. An alternative explanation is that insulin can activate mTOR by activating multiple signaling pathways which converge on mTOR. In this case, inhibition of either the MEK-ERK or the PI3-K pathways would be insufficient to completely reduce insulin-induced mTOR and therefore mTOR-dependent gene expression. Unfortunately, inhibition of both of these pathways simultaneously is not possible due to the toxicity of this combination treatment to the cell line used. This study, in combination with our previous studies on insulin-regulated gene expression, demonstrates the complexity of signaling pathways involved in insulin regulation of gene expression in general, and in the regulation of Gadd45- $\beta$ expression in particular.

Increased Gadd45- $\beta$ expression antagonizes TNF $\alpha$ cytotoxicity by suppressing TNF $\alpha$-induced JNK activation. ${ }^{27,29,30}$ Increased TNF $\alpha$ and activation of the JNK signaling pathway are known to contribute to chronic states of insulin resistance. ${ }^{53-57}$ Our recent work indicates that the JNK pathway also plays a role in TNF $\alpha$ dependent injury-induced acute hepatic insulin resistance. ${ }^{32}$ By increasing expression of Gadd45- $\beta$, insulin may be able to decrease JNK activity, decreasing the inflammatory response and insulin resistance. Thus, we hypothesize that insulin induction of Gadd45- $\beta$ gene expression is a novel mechanism for the anti-inflammatory effects of insulin.

\section{Acknowledgments}

The research was supported by grants from the National Institutes of Health (DK 62071), the Department of Defense (W81XWH-0510387), and the Veterans Administration Merit Review to Dr Messina.

\section{Disclosure}

The authors report no conflicts of interest in this work.

\section{References}

1. Messina JL. Insulin as a growth-promoting hormone. In: JL Kostyo, editor. Handbook of physiology, section 7: the endocrine system. Volume V: hormonal control of growth. New York: Oxford University Press; 1999. p. 783-811.

2. Virkamaki A, Ueki K, Kahn CR. Protein-protein interaction in insulin signaling and the molecular mechanisms of insulin resistance. $J$ Clin Invest. 1999 April;103:931-943.

3. Whitmarsh AJ, Davis RJ. Structural organization of MAP-kinase signaling modules by scaffold proteins in yeast and mammals. [Review] [33 refs]. Trends in Biochemical Sciences. 1998;23:481-485.

4. Keeton AB, Amsler MO, Venable DY, Messina JL. Insulin Signal Transduction Pathways and Insulin-induced Gene Expression. J Biol Chem. 2002;277:48565-48573.

5. Keeton AB, Bortoff KD, Bennett WL, et al. Insulin-regulated expression of Egr-1 and Krox20: dependence on ERK1/2 and interaction with p38 and PI3-kinase pathways. Endocrinology. 2003;144: 5402-5410.

6. Keeton AB, Bortoff KD, Franklin JL, Messina JL. Blockade of rapid versus prolonged extracellularly regulated kinase $1 / 2$ activation has differential effects on insulin-induced gene expression. Endocrinology. 2005;146:2716-2725.

7. Fernandez AM, Kim JK, Yakar S, et al. Functional inactivation of the IGF-I and insulin receptors in skeletal muscle causes type 2 diabetes. Genes Dev. 2001 August 1;15(15):1926-34.

8. Thomas G, Hall MN. TOR signalling and control of cell growth. Curr Opin Cell Biol. 1997;9:782-787.

9. Li J, DeFea K, Roth RA. Modulation of insulin receptor substrate-1 tyrosine phosphorylation by an Akt/phosphatidylinositol 3-kinase pathway. J Biol Chem. 1999;274:9351-9356.

10. Pessin JE, Saltiel AR. Signaling pathways in insulin action: molecular targets of insulin resistance. J Clin Invest. 2000;106:165-169.

11. Shah OJ, Anthony JC, Kimball SR, Jefferson LS. 4E-BP1 and S6K1: translational integration sites for nutritional and hormonal information in muscle. Am J Physiol Endocrinol Metab. 2000;279:E715-E729.

12. Gingras AC, Raught B, Sonenberg N. Regulation of translation initiation by FRAP/mTOR. Genes Dev. 2001;15:807-826.

13. Gingras AC, Raught B, Sonenberg N. Control of translation by the target of rapamycin proteins. Prog Mol Subcell Biol. 2001;27:174.

14. Proud CG. mTOR-mediated regulation of translation factors by amino acids. Biochem Biophys Res Commun. 2004;313:429-436.

15. Messina JL, Hamlin J, Larner J. Effects of insulin alone on the accumulation of a specific mRNA in rat hepatoma cells. J Biol Chem. 1985;260:16418-16423.

16. $\mathrm{Xu}$ J, Keeton AB, Franklin JL, et al. Insulin enhances growth hormone induction of the MEK/ERK signaling pathway. J Biol Chem. 2006;281:982-992.

17. Messina JL. Insulin and dexamethasone regulation of a rat hepatoma messenger ribonucleic acid: insulin has a transcriptional and a posttranscriptional effect. Endocrinology. 1989;124:754-761.

18. Ji S, Guan R, Frank SJ, Messina JL. Insulin inhibits growth hormone signaling via the growth hormone receptor/JAK2/STAT5B pathway. J Biol Chem. 1999;274:13434-13442.

19. Bortoff KD, Zhu CC, Hrywna Y, Messina JL. Insulin induction of pip92, CL-6 and novel mRNAs in rat hepatoma cells. Endocrine. 1997;7:199-207.

20. Messina JL. Induction of cytoskeletal gene expression by insulin. Mol Endocrinol. 1992;6:112-119.

21. Tollet P, Legraverend C, Gustafsson J-Å, Mode A. A role for protein kinases in the growth hormone regulation of cytochrome P4502C12 and insulin-like growth factor-I messenger RNA expression in primary adult rat hepatocytes. Mol Endocrinol. 1991;5:1351-1358. 
22. Messina JL, Standaert ML, Ishizuka T, Weinstock RS, Farese RV. Role of protein kinase C in insulin's regulation of c-fos transcription. J Biol Chem. 1992;267:9223-9228.

23. Messina JL, Weinstock RS. Evidence for diverse roles of protein kinase-c in the inhibition of gene expression by insulin: the tyrosine aminotransferase, albumin, and phosphoenolpyruvate carboxykinase genes. Endocrinology. 1994;135:2327-2334.

24. Messina JL. Regulation of the gamma actin gene by insulin. $J$ Cell Physiol. 1994;160:287-294.

25. Messina JL. Regulation of gene expression by insulin. In: P Cuatrecasas, SJ Jacobs, editors. Handbook of experimental pharmacology, Vol. 92 . insulin. NY: Springer-Verlag; 1990. p. 399-419.

26. Mak SK, Kultz D. Gadd45 proteins induce G2/M arrest and modulate apoptosis in kidney cells exposed to hyperosmotic stress. J Biol Chem. 2004;279:39075-39084.

27. Tornatore L, Marasco D, Dathan N, et al. Gadd45 beta forms a homodimeric complex that binds tightly to MKK7. J Mol Biol. 2008; 378:97-111.

28. Qiu W, Zhou B, Zou H, et al. Hypermethylation of growth arrest DNA damage-inducible gene 45 beta promoter in human hepatocellular carcinoma. Am J Pathol. 2004;165:1689-1699.

29. Papa S, Monti SM, Vitale RM, et al. Insights into the structural basis of the GADD45beta-mediated inactivation of the JNK kinase, MKK7/ JNKK2. J Biol Chem. 2007;282:19029-19041.

30. Papa S, Zazzeroni F, Bubici C, et al. Gadd45 beta mediates the NFkappa B suppression of JNK signalling by targeting MKK7/JNKK2. Nat Cell Biol. 2004;6:146-153.

31. Kidd LB, Schabbauer GA, Luyendyk JP, et al. Insulin activation of the phosphatidylinositol 3-kinase/protein kinase B (Akt) pathway reduces lipopolysaccharide-induced inflammation in mice. J Pharmacol Exp Ther. 2008;326:348-353.

32. Campos SP, Baumann H. Insulin is a prominent modulator of the cytokine-stimulated expression of acute-phase plasma protein genes. Mol Cell Biol. 1992;12:1789-1797.

33. Campos SP, Wang Y, Baumann H. Insulin modulates STAT3 protein activation and gene transcription in hepatic cells. J Biol Chem. 1996;271:24418-24424.

34. Xu J, Ji S, Venable DY, Franklin JL, Messina JL. Prolonged insulin treatment inhibits GH signaling via STAT3 and STAT1. J Endocrinol. 2005; 184:481-492.

35. Xu J, Kim HT, Ma Y, et al. Trauma and Hemorrhage-Induced Acute Hepatic Insulin Resistance: Dominant Role of Tumor Necrosis Factor (TNF)-alpha. Endocrinology. 2008;149:2369-2382.

36. Reks SE, Smith PH, Messina JL, Weinstock RS. Activation of PKC delta by insulin in a rat hepatoma cell line. Endocrine. 1998;8:161-167.

37. Nelson JWed. Alpha Innotech hands on application note \#26. 1-1-1999. San Leandro, CA, Alpha Innotech Corporation. Ref Type: Pamphlet

38. Kendrick NC, Johansen JJ, Lee PR, Santek DA. Optimization of an HP Scanjet for quantification of protein electrophoresis gels. Anal Biochem. 1994;219:297-304.

39. Keeton AB, Messina JL. Modulation of Elk-dependent-transcription by Gene33. J Cell Biochem. 2005;94:1190-1198.

40. Tong T, Fan W, Zhao H, et al. Involvement of the MAP kinase pathways in induction of GADD45 following UV radiation. Exp Cell Res. 2001;269:64-72.
41. DeHaan RD, Yazlovitskaya EM, Persons DL. Regulation of p53 target gene expression by cisplatin-induced extracellular signal-regulated kinase. Cancer Chemother Pharmacol. 2001;48:383-388.

42. Oldham S, Hafen E. Insulin/IGF and target of rapamycin signaling: a TOR de force in growth control. Trends Cell Biol. 2003;13:79-85.

43. Schmelzle T, Hall MN. TOR, a central controller of cell growth. Cell. 2000;103:253-262.

44. Fafournoux P, Bruhat A, Jousse C. Amino acid regulation of gene expression. Biochem J. 2000;351:1-12.

45. van Sluijters DA, Dubbelhuis PF, Blommaart EF, Meijer AJ. Aminoacid-dependent signal transduction. Biochem J. 2000;351:550.

46. Hornberger TA, Stuppard R, Conley KE, et al. Mechanical stimuli regulate rapamycin-sensitive signaling by a phosphoinositide 3-kinase, protein kinase B and growth factor independent mechanism. Biochem J. 2004;380:795-804.

47. Fang Y, Vilella-Bach M, Bachmann R, Flanigan A, Chen J. Phosphatidic acid-mediated mitogenic activation of mTOR signaling. Science. 2001;294:1942-1945.

48. Kam Y, Exton JH. Role of phospholipase D1 in the regulation of mTOR activity by lysophosphatidic acid. FASEB J. 2004;18:311-319.

49. Lornejad-Schafer MR, Schafer C, Graf D, Haussinger D, Schliess F Osmotic regulation of insulin-induced mitogen-activated protein kinase phosphatase (MKP-1) expression in H4IIE rat hepatoma cells. Biochem J. 2003;371:609-619.

50. Von Manteuffel SR, Gingras AC, Ming XF, Sonenberg N, Thomas G. 4E-BP1 phosphorylation is mediated by the FRAP-p $70^{\mathrm{s} 6 \mathrm{k}}$ pathway and is independent of mitogen-activated protein kinase. Proc Natl Acad Sci US A. 1996;93:4076-4080.

51. Von Manteuffel SR, Dennis PB, Pullen N, Gingras AC, Sonenberg N, Thomas G. The insulin-induced signalling pathway leading to S6 and initiation factor $4 \mathrm{E}$ binding protein 1 phosphorylation bifurcates at a rapamycin-sensitive point immediately upstream of $\mathrm{p} 70^{\mathrm{s} 6 \mathrm{k}}$. Mol Cell Biol. 1997; 17:5426-5436.

52. Takuwa N, Fukui Y, Takuwa Y. Cyclin D1 expression mediated by phosphatidylinositol 3-kinase through mTOR-p70(S6K)-independent signaling in growth factor-stimulated NIH $3 \mathrm{~T} 3$ fibroblasts. Molecular and Cellular Biology. 1999;19:1346-1358.

53. Hirosumi J, Tuncman G, Chang L, et al. A central role for JNK in obesity and insulin resistance. Nature. 2002;420:333-336.

54. Bennett BL, Satoh Y, Lewis AJ. JNK: a new therapeutic target for diabetes. Curr Opin Pharmacol. 2003;3:420-425.

55. Nakatani Y, Kaneto H, Kawamori D, et al. Modulation of the JNK pathway in liver affects insulin resistance status. J Biol Chem. 2004;279:45803-45809.

56. Ogston D, McAndrew GM. Fibrinolysis in obesity. Lancet. 1964; 2:1205-1207.

57. Tuncman G, Hirosumi J, Solinas G, Chang L, Karin M, Hotamisligil GS. Functional in vivo interactions between JNK1 and JNK2 isoforms in obesity and insulin resistance. Proc Natl Acad Sci US A. 2006;103:10741-10746.
Hepatic Medicine: Evidence and Research

\section{Publish your work in this journal}

Hepatic Medicine: Evidence and Research is an international, peerreviewed, open access journal covering all aspects of adult and pediatric hepatology in the clinic and laboratory including the following topics: Pathology, pathophysiology of hepatic disease; Investigation and treatment of hepatic disease; Pharmacology of drugs used for

\section{Dovepress}

the treatment of hepatic disease. Issues of patient safety and quality of care will also be considered. The manuscript management system is completely online and includes a very quick and fair peer-review system, which is all easy to use. Visit http://www.dovepress.com/ testimonials.php to read real quotes from published authors. 